\title{
Enhanced sedimentation beneath particle- laden flows in lakes and the ocean due to double-diffusive convection
}

\author{
Shahrzad Davarpanah Jazi and Mathew G. Wells
}

\author{
Version Post-print/accepted manuscript \\ Citation Davarpanah Jazi, S., and M. G. Wells (2016), Enhanced sedimentation \\ (published version) beneath particle-laden flows in lakes and the ocean due to double- \\ diffusive convection, Geophys. Res. Lett., 43, 10,883-10,890, \\ doi:10.1002/2016GL069547.
}

How to cite TSpace items

Always cite the published version, so the author(s) will receive recognition through services that track citation counts, e.g. Scopus. If you need to cite the page number of the author manuscript from TSpace because you cannot access the published version, then cite the TSpace version in addition to the published version using the permanent URI (handle) found on the record page.

This article was made openly accessible by $U$ of $T$ Faculty. Please tell us how this access benefits you. Your story matters. 


\section{Title page:}

Enhanced sedimentation beneath particle-laden flows in lakes and the ocean due to doublediffusive convection.

Corresponding author: Shahrzad Davarpanah Jazi, Department of Physical and Environmental Sciences, University of Toronto Scarborough, 1265 Military Trail, Toronto, ON, M1C 1A4, Canada. (sh.davarpanahjazi@mail.utoronto.ca)

Mathew G. Wells, Department of Physical and Environmental Sciences, University of Toronto Scarborough, Toronto, ON, Canada. 


\section{Three key points:}

- Double-diffusive processes can increase sedimentation rates 10 times above the Stokes settling velocity.

- The strength of convection is a strong function of density ratio, and is greatest for density ratios slightly above unity.

- The process of double-diffusive convection should dominate sedimentation of material in lake interflows. 


\section{$\underline{\text { Abstract: }}$}

The transport rate of particles beneath sediment-laden overflows and interflows in lakes and the ocean can be enhanced by double-diffusive and settling-driven convection. In previous experiments with sediment-laden fluid overlaying a saline layer, visual measurements could only be made in the optically clear lower-layer. Hence there was difficulty distinguishing the two processes, hindering predictions of when enhanced sedimentation occurs. We used an Acoustic Doppler Velocimeter (ADV) to measure velocities and turbulence above and below the initial sediment/salt interface. The velocity of the sediment fingers in the lower layer were always larger than the Stokes settling velocity of the particles, leading to an asymmetry in the flow field of the two convective layers. Sediment fingers only dominated when there were marginal density differences between the two layers. We conclude that double-diffusive sediment fingers control sedimentation beneath interflows in most lakes, whereas settling-driven convection is dominant in most oceanic overflows. 


\section{$\underline{\text { Index terms and key words: }}$}

Double-diffusive convection

Settling-driven convection

Sediment fingers

Interflows

Overflows 


\section{Text:}

\section{Introduction}

Double-diffusive convection has been used to rationalize increased sedimentation rates of fine particles in a number of situations in stratified fluid bodies, such as beneath buoyant river plumes [Hoyal et al., 1999a, 1999b; Parsons et al., 2001; Snow \& Sutherland, 2014], and in the atmosphere under volcanic ash plumes [Carazzo and Jellinek, 2012, 2013; Manzella et al., 2015]. There is observational evidence of enhanced sedimentation near the mouth of the rivers, in both the coastal ocean [Nowacki et al., 2012] and lakes [Scheu et al., 2015], where the apparent particle settling rate is larger than that based on the Stokes settling velocity of a single particle. However it is not clear whether such enhanced settling is due to flocculation [Rouhnia \& Strom, 2015], double-diffusive convection [Hoyal et al., 1999a; Parsons et al., 2001] or settling-driven convection [Bradley, 1965; Hoyal et al., 1999b]. The sediment deposition rate is critical in determining the fate of particles that settle beneath an overflow (hypopycnal flow) or interflow (mesopycnal flow). For example, the small settling velocity of a fine particle $\left(<0.01-1 \mathrm{~mm} \mathrm{~s}^{-1}\right)$, described by the Stokes settling velocity $\left(\mathrm{w}_{\mathrm{p}}\right)$, would suggest that these particles deposit far away from the mouth of the river, as generally horizontal advection velocities greatly exceed these settling velocities [Horner-Devine et al. 2015]. However, field observations usually suggest that deposition occurs much closer to river mouths [Warrick et. al., 2008], implying that other physical mechanisms must enhance settling rates.

Previous experiments on sediment fingering estimated the velocities of the sediment fingers using series of photos [Houk \& Green, 1973; Green, 1987; Chen, 1997; Maxworthy, 1999; Hoyal et al., 1999a, 1999b; Parsons \& Garcia, 2000; Parsons et al., 2001] and found that vertical sediment transport velocities can be an order of magnitude higher than the Stokes settling velocity. A critical limitation of all these experiments was that the sediment bearing layer is optically opaque, which greatly hampered an understanding of the physical processes at work. While there has been great progress in direct numerical simulations of this process [Yu et al., 2014; Burns \& Meiburg, 2015], there is a paucity of solid experimental or theoretical descriptions of the process, which limits our understanding of sediment transport in stratified systems. In this experimental study we investigate the mechanisms responsible for the enhanced sediment transport rates of noncohesive particles and determine how to distinguish enhanced sedimentation due to doublediffusive fingering from settling-driven convection.

In the absence of flocculation and shear, two related processes of enhanced particle sedimentation could occur beneath a sediment-laden flow, namely double-diffusive convection (illustrated in Figure 1a) and settling-driven convection (illustrated in Figure 1b). In both cases an enhanced sedimentation occurs, with vigorous convection driven by descending plumes of sediment-laden material into the lower layer. Visually these two processes look similar in this layer, and it has been difficult to distinguish them in previous experiments [Chen, 1997; Parsons et al., 2001; Hoyal et al., 1999a, 1999b]. 

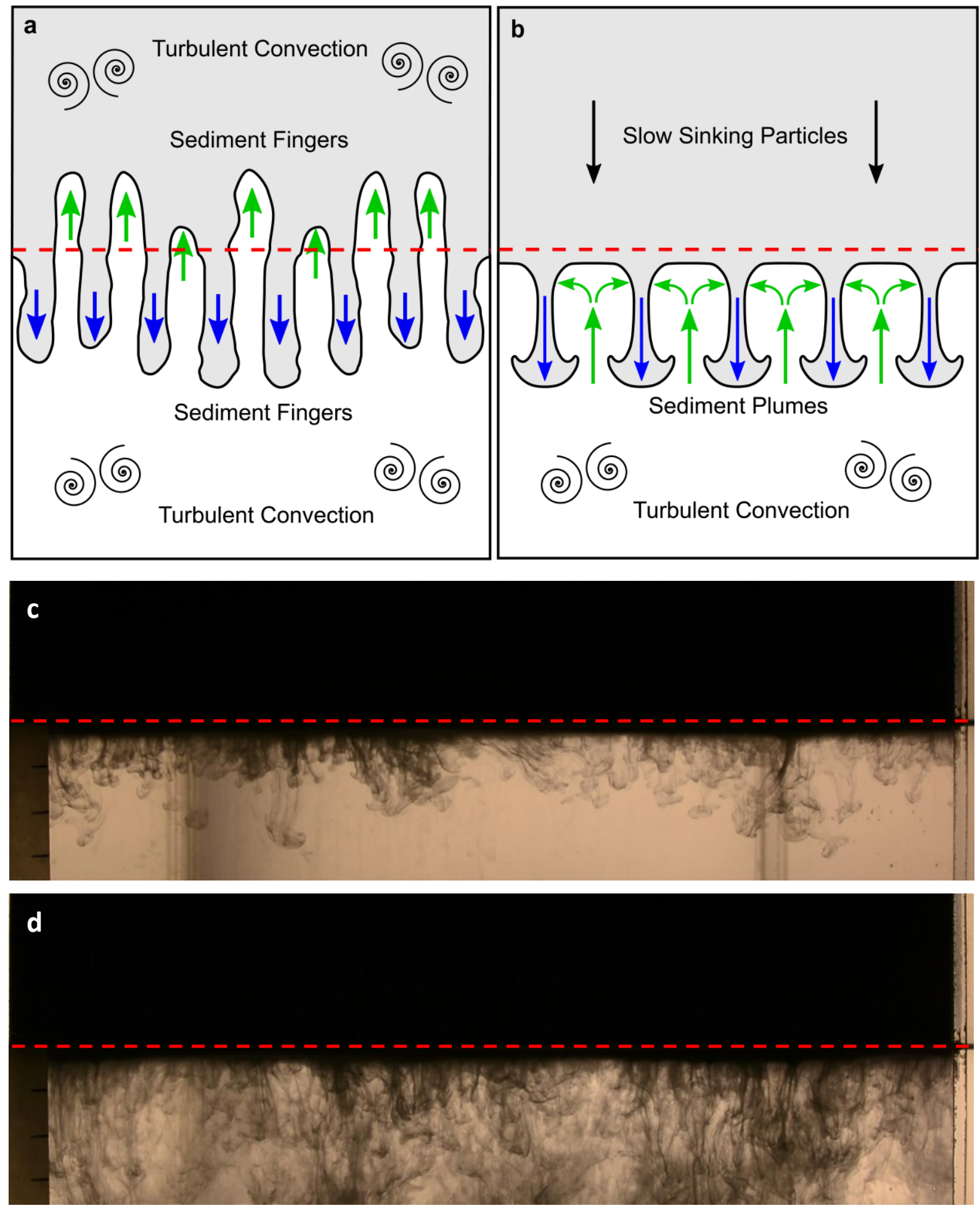

Figure1. Schematic of circulation from (a) double-diffusive "sediment fingering" whereby convection occurs in both layers and (b) settling-driven convection, whereby convection only occurs in the lower layer. The red line indicates the initial density interface between layers. The green and blue arrows show the movement direction of salt water and sediment particles respectively. Photographs of flow's behavior for initial value of $R_{\rho}=3.33$ (c) $28 \mathrm{~s}$ and (d) $70 \mathrm{~s}$ after pulling the barrier. 
When a lighter sediment-laden layer floats above a heavier layer of saline water, a doublediffusive "sediment fingering" instability can arise due to the diffusion of salt (or heat) being much faster than the Brownian diffusion of sediment. This results in rapidly descending fingers of sediment beneath the sediment bearing layer (as shown in Figure 1a) and is conceptually similar to the well-studied "salt fingering" mechanism [Schmitt, 1994, Traxler et al., 2011]. A key feature of double-diffusive convection is that fingers are both rising and descending through the interface, so that there is a net transport of sediment downward and a smaller transport of salt upward. This means the net density flux is up-gradient, and the total density gradient actually increases with time [Schmitt, 1994]. An important feature of sediment fingering is that vigorous convection can occur in both the optically opaque top layer as well as the clear lower layer. The vigor of convection is also a strong function of both the concentration of the sediment, as well as the ratio of the density anomaly. The most vigorous convection due to double-diffusive convection is predicted to occur when there is only marginal stability, and the top layer is only slightly less dense than the lower layer [Yu et al., 2014; Burns \& Meiburg, 2015; Traxler et al., 2011]. This has been seen in some previous experimental studies that tried to characterize sediment finger structures [Houk \& Green, 1973; Green, 1987; Chen, 1997; Maxworthy, 1999; Hoyal et al., 1999a, 1999b; Parsons \& Garcia, 2000; Parsons et al., 2001]. Some estimated the mean velocity of fingers to be an order of magnitude higher than $W_{P}$ and showed that it was a function of the density ratio between the layers, with larger finger velocities occurring when the ratio is close to one [Houk \& Green, 1973; Green, 1987; Chen, 1997; Parsons \& Garcia, 2000; Parsons et al., 2001].

A second process that occurs beneath a layer of sediment-laden fluid is settling-driven convection; here sediment transport velocities are enhanced over the Stokes velocity by the reason that a dense plume of sediment-laden fluid can descend much faster than an individual particle [Bradley, 1965; Kuenen, 1968; Hoyal et al., 1999b]. When a sediment-laden fluid overlies a denser saline layer, the accumulation of particles just below the interface can develop a gravitationally unstable bulk density profile that produces Rayleigh-Taylor instability at the sediment front [Carey, 1997; Blanchette \& Bush, 2005; Yu et al., 2013, 2014; Burns \& Meiburg, 2012, 2015]. This process is shown schematically in Figure $1 \mathrm{~b}$, where settling-driven convection leads to convective sediment plumes below the interface driving vigorous convection. Above the interface however, there should be no convection and the only motion is the slow steady downward settling of particles at their terminal velocity, as well as much weaker return flow of interstitial water. Additionally there would be no significant vertical transfer of salinity into the top layer, beyond the small molecular diffusive flux of salt. As the convection in the lower layer is driven by the flux of particles at the interface, the vigor of the convection should depend only upon the settling rate, and the difference in sediment concentration between the two layers. Most significantly for settling-driven convection there should be no dependence of the convection upon the salinity difference. 
All past experimental studies were based on qualitative visual methods, which were limited to the optically clear lower layer and made it difficult to determine when double-diffusive or settlingdriven convection occurred. By measuring the turbulence characteristics in the sediment-laden and saline layers of a two-layer configuration, we can determine which turbulence conditions are consistent with double-diffusive or settling-driven convection. Our data cover a geophysical relevant range of salinity and sediment concentration differences, which we used to provide a sedimentation process regime diagram to predict the occurrence of enhanced sedimentation beneath overflows and interflows in oceans and lakes.

\section{Methodology}

The experiments were conducted in a transparent Plexiglas tank with the dimensions of $22.5 \times$ $22.5 \times 48.2 \mathrm{~cm}$. A layer of turbid fluid was introduced over a clear saline layer with identical heights of $18.6 \mathrm{~cm}$. To prevent the mixing of the two initially quiescent layers before starting the actual experiment, a sliding flexible barrier with a thickness of $0.270 \pm 0.005 \mathrm{~mm}$ was used, similar to that in experiments of Chen [1997], Hoyal et al. [1999a, 1999b] and Parsons et al. [2001]. Tap water, equilibrated to the room temperature $\left(20 \pm 0.5^{\circ} \mathrm{C}\right)$, was used to prepare the salt solution and sediment suspension. Equal volumes of saline and sediment-laden fluid were transferred into the Plexiglas tank in two layers, as shown in Figure S1 in the supporting information section. A small mixer in this tank kept the sediment-laden layer homogenous. To inhibit the turbulence produced by the mixer, each experiment commenced with the gentle removal of the barrier $120 \mathrm{~s}$ after the small mixer was turned off. This produced a sharp density interface for the initial condition of each experiment.

The sediment used in the experiment was Silicon Carbide ( $\mathrm{SiC}$ ) grinding powder, as used previously in the experiments of Hoyal et al. [1999a, 1999b] and Chen [1997]. These particles were monodispersed and non-cohesive. They did not flocculate in a saline solution, unlike the clay suspension discussed by Griffiths [1979]. The sediment particles had a median diameter of $7.8 \mu \mathrm{m}$, and their size distribution (illustrated in Figure S2 in the supporting information section), was determined using a S3500 Microtrac Analyzer by Geoscience laboratories. The SiC particles had a density of $3210 \mathrm{~kg} \mathrm{~m}^{-3}$, and the Stokes settling velocity of the median particle size was 0.077 $\mathrm{mm} \mathrm{s}^{-1}$. The size distribution implies that there will be some distribution in settling velocities. Evaporated high purity, food grade salt was used for making the saline solution in the lower layer.

The density of the fluid is assumed to be a linear function of both sediment and salt concentrations. This density is therefore determined as $\rho=\rho_{0}+\Delta \rho_{S}+\Delta \rho_{C}$, where $\rho_{0}$ is the density of clear fresh water at $20^{\circ} \mathrm{C}\left(998.2 \mathrm{~kg} \mathrm{~m}^{-3}\right), \Delta \rho_{\mathrm{S}}$ is the added density due to the added salt and $\Delta \rho_{\mathrm{C}}$ $=\gamma \mathrm{C}$ is the added density due to the added mass fraction of sediment $(\mathrm{C})$, in which $\gamma$ is the density expansion coefficient for sediment. Here $\gamma$ is defined as $\left(\rho_{C}-\rho_{0}\right) / \rho_{C}$, where $\rho_{C}$ is the density of particles $\left(\mathrm{kg} \mathrm{m}^{-3}\right) . \Delta \rho_{\mathrm{S}}$ is defined using the empirical polynomials in Ruddick \& Shirtcliffe [1979]. The characterization of the experiments was based on different density ratios of the two layers, 
defined as $\mathrm{R}_{\rho}=\Delta \rho_{\mathrm{S}} / \Delta \rho_{\mathrm{C}}$. We used 72 experiments to study the density ratio range of $1.03 \leq \mathrm{R}_{\rho} \leq$ 18.06. Temperature was kept constant through all experiments to obtain a controllable twocomponent salt-sediment configuration (similar to the experiments of Hoyal et al. [1999b]). For an additional 7 experiments with constant $\Delta \rho_{\mathrm{S}}$ and variable $\Delta \rho_{\mathrm{C}}$ (so that $1.03 \leq \mathrm{R}_{\rho} \leq 18.06$ ), the rate of change in salinity was used to estimate salt fluxes. This was done by collecting $30 \mathrm{ml}$ fluid samples from the centre of each layer every $250 \mathrm{~s}$ for the first $1250 \mathrm{~s}$ of each experiment. The conductivity was measured using an Oakton PC700 meter and salinity was then determined using equations of Fofonoff \& Millard Jr, [1987].

To measure the time-series of vertical velocity in each of the two layers, a Nortek Vectrino+ Acoustic Doppler Velocimeter (ADV) was used to sample a volume of fluid centered at either 1.5 $\mathrm{cm}$ above or below the density interface. The Vectrino+ ADV has four receivers that are slanted at $30^{\circ}$ from the axis of the transducer and focus on a common cylindrical sample of width $6 \mathrm{~mm}$ and length $8 \mathrm{~mm}$, which is $50 \mathrm{~mm}$ away from the probes. With four receivers, two independent estimates of vertical velocity can be made and the accuracy of measurements is improved. Due to their sampling geometry, the ADVs provide very accurate measurements of vertical velocity (w), compared to the horizontal components. Theoretically the noise level of the vertical velocity components is 13.9 times lower than the noise level of the horizontal velocity component in a 4 beam ADV [Doroudian et al., 2010]. While the accuracy of horizontal velocities is quoted as \pm 1 $\mathrm{mm} \mathrm{s}^{-1}$ [Nortek $A S, 2004$ ], the vertical velocity has been estimated to have an accuracy of at least ten times better, i.e. $\pm 0.1 \mathrm{~mm} \mathrm{~s}^{-1}$ [Devi \& Kumar, 2015]. In our experiments, we confirmed that the rms value of the difference between the two estimates of vertical velocity was always less than $0.1 \mathrm{~mm} \mathrm{~s}^{-1}$, and hence was similar to the resolution of the instrument of $0.1 \mathrm{~mm} \mathrm{~s}^{-1}$. As velocities are measured due to the Doppler shift from the acoustic beams reflected by suspended particles in water, the velocity measured by the ADV is technically the velocity of the particles rather than that of the water [Nortek AS, 2004]. Moreover, since the particles in our experiments had a mean settling velocity of $-0.077 \mathrm{~mm} \mathrm{~s}^{-1}$, any velocity greater than the Stokes settling velocity was indicative of a convective motion of the fluid carrying sediment. Our sampling rate was $50 \mathrm{~Hz}$, and the raw velocity data were filtered with the use of WinADV software [Whal, 2000], with a minimum signal to noise ratio of $15 \mathrm{~dB}$ and a minimum correlation coefficient between transmitted and received pulses of $70 \%$ [Nortek AS, 2004].

Previous experiments have shown that turbulence can disrupt double-diffusive convection in experiments [Wells \& Griffiths, 2003]. To this end the barrier was removed as slowly as possible to minimize shear. Furthermore, the first $150 \mathrm{~s}$ of each experiment were not considered in our results to minimize the effect of initial shear caused by the sliding barrier upon the flow characteristics and allow any turbulence from the barrier to decay. Using the time series of vertical velocity data, we characterized the turbulence strength in each layer as $\mathrm{w}_{r m s}=\sqrt{\overline{\left(\mathrm{w}^{\prime}(\mathrm{t})\right)^{2}}}$. Here $w^{\prime}(t)$ is the turbulent velocity fluctuation determined as $w^{\prime}(t)=w(t)-\bar{w}$, where $\bar{w}$ is the $500 s$ 
time average. We choose to average over a timescale of $500 \mathrm{~s}$ as it is long enough to capture the flow variability, but short compared to the timescale of approximately $2500 \mathrm{~s}$ that particles with a mean settling velocity of $0.077 \mathrm{~mm} \mathrm{~s}^{-1}$ would take to fall over a depth of $18.6 \mathrm{~cm}$. Experiments were conducted at least twice for precision purposes and averages of $\mathrm{w}_{r m s}$ were calculated for each value of $\mathrm{R}_{\rho}$. The variation in $\mathrm{w}_{r m s}$ between experiments was less than $10 \%$ indicating that this is a robust parameter to describe the vigor of convection.

\section{Results and Discussion}

Our combination of flow visualizations and acoustic Doppler velocimetry extends previous observations of sedimentation regimes in the lower layer to determine when double-diffusive processes are present in the optically opaque top layer. Figures 1c and 1d show photographs of an experiment for $\mathrm{R}_{\rho}=3.33$ at two different times. Movie $\mathrm{S} 1$ in the supporting information also displays the behavior of the flow for $\mathrm{R}_{\rho}=3.33$. In Figure 1c, taken $28 \mathrm{~s}$ after pulling the barrier, sediment plumes with mushroom shaped ends and width of about $1 \mathrm{~cm}$ can be observed. They formed gradually below the interface and dispersed as they reached the middle of the saline layer. After around $70 \mathrm{~s}$, a large number of very long and thin streaks formed vertically (Figure 1d) that had width of a few millimetres. They formed continuously and moved horizontally, while the bottom layer became more opaque because of the sediment settling from the top layer. These two distinct convective regimes were comparable to previous studies [Hoyal et al., 1999b; Parsons et al., 2001]. Figure 1c was similar to 'settling-driven convection' or 'convective sedimentation' regime denoted by Hoyal et al. [1999b], whereas Figure 1d was the same as the 'leaking' regime discussed by Parsons et al. [2001]. In our experiments $\mathrm{R}_{\rho}$ was increasing as the sediment gradient ran down with time, so in all our experiments with initial $R_{\rho}>1.2$, both 'settling-driven convection' and 'leaking' regimes could occur at different times. On the other hand, the experiments with $\mathrm{R}_{\rho}=1.03$ had very active convection. Movie $\mathrm{S} 2$ in the supporting information section shows that for $R_{\rho}=1.03$, the lower layer rapidly became optically opaque from sediments, so we infer that particles were transported to the lower layer with the high turbulence rates after about $20 \mathrm{~s}$. Visual comparison of the two movies clearly indicates that the vertical sediment flux is much stronger when $R_{\rho} \sim 1$. The time it takes (from the removal of the barrier) for the bottom layer to turn completely dark in experiment with $R_{\rho}=1.03$ is $168 \mathrm{~s}$, whereas for $R_{\rho}=3.33$ this time is $425 \mathrm{~s}$. This qualitative measure implies that sediment flux is at least four times greater for low initial density ratios. The visual observation of increase in transport rates at low density ratio was seen throughout all 72 experiments, and is consistent with our main hypothesis that sediment fingers increase transport of sediment at low density ratio values compared to the weaker turbulent transport associated with settling-driven convection.

The measured time-series of vertical velocity, above and below the initial density interface show distinct behaviour for low and high $\mathrm{R}_{\rho}$ (Figure 2 ). These velocities have been normalized by the Stokes settling velocity magnitude $\left(0.077 \mathrm{~mm} \mathrm{~s}^{-1}\right)$. It is striking that in the first $500 \mathrm{~s}$, the normalized velocities are as high as 100 times the Stokes settling velocity. At later times the 
convection diminished once most of the sediment had fallen into the lower layer, and it is clear that the vertical velocities converge to the Stokes settling velocity of the particles, (i.e., normalized value of -1). The two main differences between the low and high $\mathrm{R}_{\rho}$ can be seen by comparing Figures $2 \mathrm{a}$ and $2 \mathrm{~b}\left(\mathrm{R}_{\rho}=1.03\right)$ with corresponding Figures $2 \mathrm{c}$ and $2 \mathrm{~d}\left(\mathrm{R}_{\rho}=18.06\right)$. First, the magnitude of convective velocities for $R_{\rho}=1.03$ is five times larger than $R_{\rho}=18.06$. Second, there are differences in fluctuations of velocity (relative strengths of turbulence) in the top and bottom layers of the flow for the low and high $\mathrm{R}_{\rho}$. The time-series for experiments with $\mathrm{R}_{\rho}=1.03$, have vigorous convection in both the top and bottom layers with the same range of velocity magnitudes, similar to the schematic representation of sediment fingering in Figure 1a. In contrast the timeseries for $\mathrm{R}_{\rho}=18.06$ have much smaller convective velocities in the top layer than the bottom layer, consistent with Figure $1 \mathrm{~b}$.
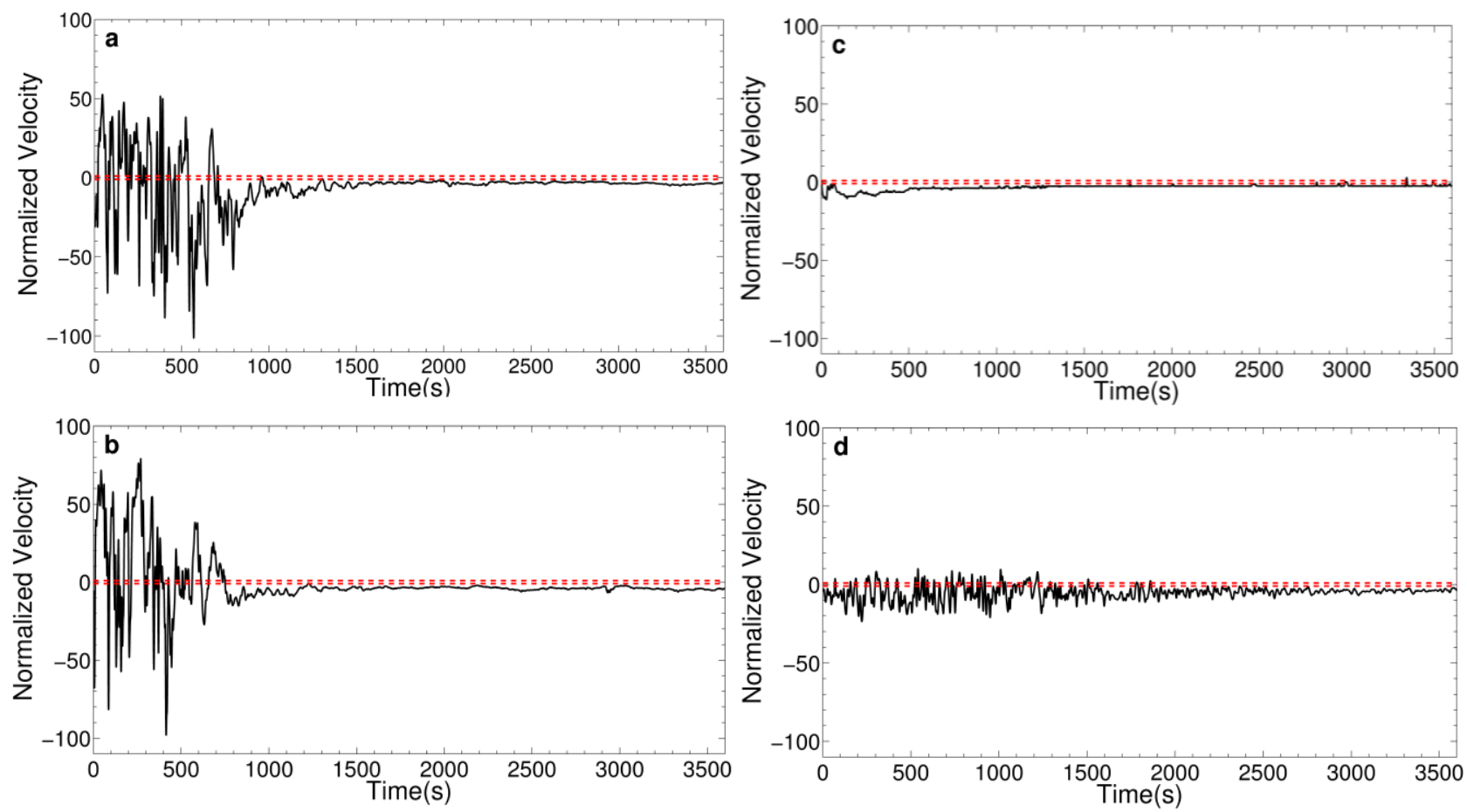

Figure 2: The vertical velocity time series normalized by the Stokes settling velocity for the (a) top layer and (b) bottom layer for low initial density ratio $\left(R_{\rho}=1.03\right)$ and $(c)$ and $(d)$ High initial density ratio $\left(R_{\rho}=18.06\right)$. The red lines indicate where the velocity (negative or positive) is equal to the Stokes settling velocity.

There is a systematic variation in the relative strength of convection in the top and bottom layers, which can be used as an indicator of when double-diffusive convection occurs and when settling-driven convection dominates. The variation of the turbulence strength in both layers (in the first $500 \mathrm{~s}$ of each experiment) as a function of $\mathrm{R}_{\rho}, \Delta \rho_{\mathrm{C}}$ and $\Delta \rho_{\mathrm{s}}$ are plotted in Figure 3a. This figure shows that in general there is greater turbulence strength in the bottom layer than the top layer, except for the experiments with $\mathrm{R}_{\rho}=1.03$, where there is nearly equal turbulence in both layers. Moreover, with the decrease of $\mathrm{R}_{\rho}$, there is an increasing trend of turbulence strength in both layers which reaches its highest value at $R_{\rho}=1.03$. The presence of high turbulence in both 
layers for $\mathrm{R}_{\rho}=1.03$ suggests that double-diffusive convection is the dominant mechanism leading to the formation of convective sediment fingers close to the density interface. As we discard the $150 \mathrm{~s}$ of data immediately after barrier extraction, this result should not be influenced by any small initial turbulence. This signature of double-diffusive convection only occurs near the diagonal line where $R_{\rho}=1$ (Figure 3a). For $R_{\rho}>1.2$ the dominating process is settling-driven convection, which is demonstrated by two important trends in Figure 3a. First, increasing the salinity contrast $(\Delta \rho s)$ in Figure $3 \mathrm{a}$ has no significant effect on the magnitude of turbulence strength in both layers. Second, increasing the sediment contrast $\left(\Delta \rho_{\mathrm{C}}\right)$ has a substantial effect on the magnitude of turbulence strength in both layers, especially in the bottom layer. Both of these trends are consistent with settling-driven convection dominating the flow for $R_{\rho}>1.2$. Furthermore, our conductivity measurements indicated a salt flux of $5 \times 10^{-5}$ to $10^{-4} \mathrm{~kg} / \mathrm{m}^{2} / \mathrm{s}$ for $\mathrm{R}_{\rho}=1.03$ and $9 \times$ $10^{-7}$ to $1.5 \times 10^{-5} \mathrm{~kg} / \mathrm{m}^{2} / \mathrm{s}$ for $1.2<\mathrm{R}_{\rho} \leq 18.06$. This determined that there was a significant salt flux between the layers, which is at least 10 times higher for small $R_{\rho}$ values $\left(R_{\rho}=1.03\right)$ than for $1.2<$ $\mathrm{R}_{\rho} \leq 18.06$. In all cases the salt fluxes were one or two orders of magnitude larger than predicted molecular diffusive fluxes between the layers, which were in the range of $5.38 \times 10^{-7}$ to $2.1 \times 10^{-6}$ $\mathrm{kg} / \mathrm{m}^{2} / \mathrm{s}$. The decrease of the salt flux with increases of $R_{\rho}$ is also an indication of double-diffusive effects.
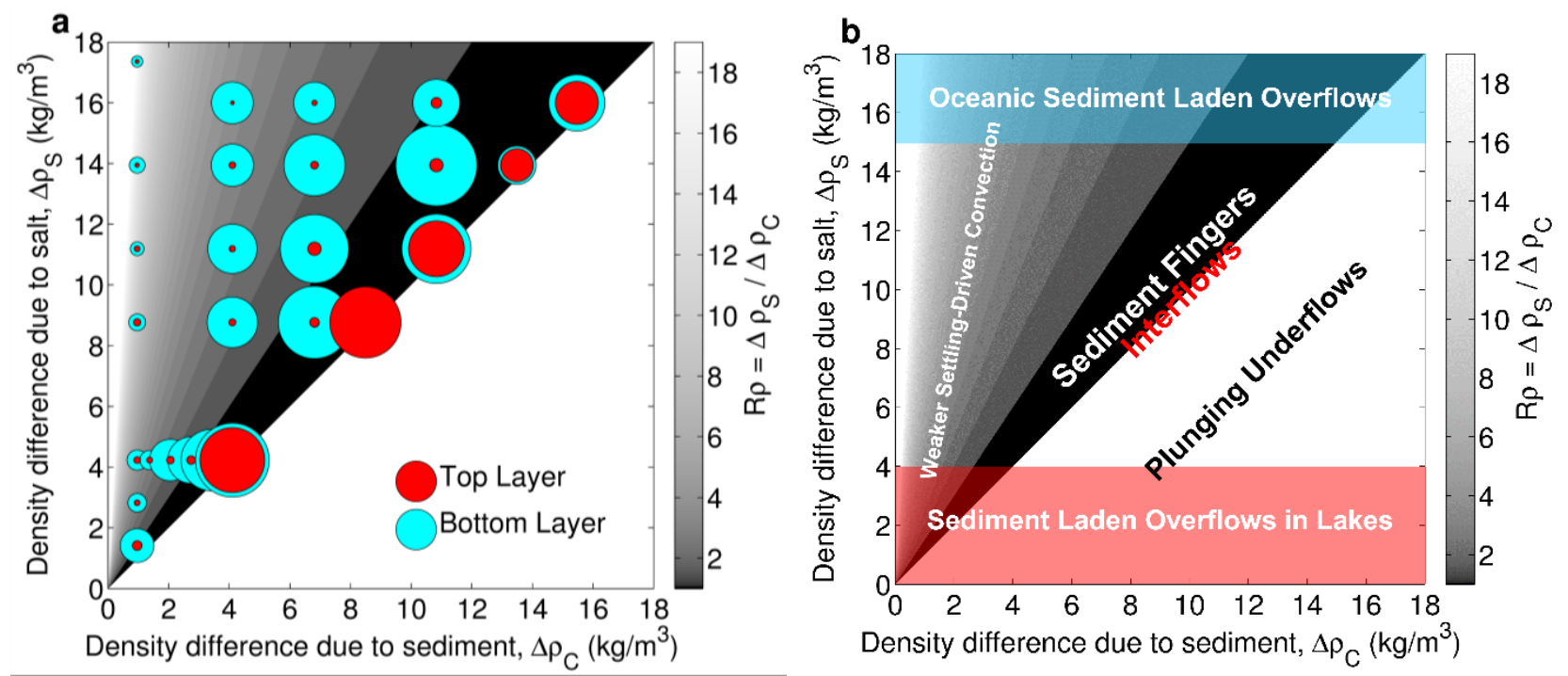

Figure 3. (a) The turbulence strength normalized by the Stokes settling velocity in the first 500s for the top and bottom layers as a function of the density difference due to sediment and salinity. The diameter of the red and blue circles in lower-right corner represents normalized turbulence strength of 27.5. (b) A regime diagram showing the occurrence of overflows, underflows and interflows in geophysically relevant situations.

\section{Summary and Conclusion}

Our main observation is that the convective velocities that transport sediment below a sedimentladen fluid can greatly exceed Stokes settling velocities for all experiments. When $R_{\rho}>1.2$, the strength of convection appears to be dominated by the sediment difference across the interface, consistent with settling-driven convection. In contrast, sediment fingers due to double-diffusive 
convection can drive convection above and below a density interface only for $\mathrm{R}_{\rho}=1.03$. We note that this conclusion is only for $\mathrm{SiC}$ particles with $7.8 \mu \mathrm{m}$ diameter, and we anticipate that slower settling particles (i.e., smaller or lighter) would have a greater range of $\mathrm{R}_{\rho}$ where double-diffusive convection dominates. Our measurements indicate that the velocity in the lower layer was larger than the Stokes settling velocity of particles, which is consistent with visual estimations of Houk \& Green [1973], Green [1987], Parsons \& Garcia [2000] and Parsons et al. [2001]. Furthermore, our conductivity measurements confirm the evidence of salt fluxes into the upper layer for low values of $R_{\rho}$. The rate of change of salinity in the top and bottom layers show that, in the first 500 $\mathrm{s}$ of our experiments the flux of salt into top layer is much greater in experiments with $\mathrm{R}_{\rho}=1.03$, compared to when $1.2<\mathrm{R}_{\rho} \leq 18.06$. This is consistent with double-diffusive sediment fingering being active only for $\mathrm{R}_{\rho}$ close to unity.

Sediment-laden underflows (hyperpycnal flows) and interflows are rare in the coastal ocean, due to the large density difference between fresh water and seawater $\left(\Delta \rho \sim 20 \mathrm{~kg} \mathrm{~m}^{-3}\right)$ as rivers generally do not contain enough sediment, except during extreme rainfall events [Mulder \& Syvitski 1995; Mulder \& Chapron, 2011; Hinat et al., 2015]. Thus, when rivers flow into the ocean, they usually result in buoyant overflows having $R_{\rho} \gg 1$ and hence; our experiments suggest that settling-driven convection is the dominant sedimentation mechanism for buoyant river plumes in the ocean. On the rare occasions that sediment-laden interflows occur in the ocean, it is often from dredging in stratified waters [Wu et al., 2006] or lofting of turbidity currents [Meiburg \& Kneller, 2010]. In contrast to the coastal ocean, thermal stratification in lakes is much weaker, and the largest thermal differences between $20^{\circ} \mathrm{C}$ and $4^{\circ} \mathrm{C}$ water are of order $\Delta \rho \sim 1.7 \mathrm{~kg} \mathrm{~m}^{-3}$. Hence, a sediment-laden river entering a stratified lake needs far less sediment load to form an underflow or interflow than in the coastal ocean. Thus, there are numerous observations of sediment-laden interflows in lakes, such as the Rhône River flowing into Lake Geneva [Giovanoli, 1990], in Lake Ohau [Cossu et al., 2015], Lake Maggiore [Scheu et al., 2015] and Quesnel Lake [Petticrew et al., 2015]. By definition an interflow occurs at its depth of neutral buoyancy, where the density difference between layers is minimal and hence $R_{\rho} \sim 1$. Therefore, based on our regime diagram, double-diffusive convection is the primary mechanism controlling sedimentation in interflows causing the sediment particles to accumulate much faster near the mouth of the river, whereas in oceanic overflows it is the settling-driven convection that dominates resulting in the settling of particles under the gravity force farther away from the mouth of the river. As the turbulent velocity increases with sediment difference, we also infer that sediment transport will be greatest at low $\mathrm{R}_{\rho}$, where double-diffusive convection dominates. This conclusion about the increase in sediment transport rates is also corroborated by the Movies S1 and S2 in the supporting information, which clearly show an increase in sediment transport rates with decreasing density ratio. We hope that our turbulence ratio criteria coupled with field measurements of $R_{\rho}$ can be used to guide future monitoring of sedimentation processes by sedimentologists, and help to infer which of these two processes is dominating. This conclusion could be carefully tested in future field work using microstructure profiles to measure turbulence profiles, and careful measurements of both sediment, 
temperature and salinity profiles beneath sediment-laden overflows and interflows. Turbulent fluxes of sediment might also be measured directly from correlation of sediment concentrations and velocity fluctuations using acoustic devices.

\section{Acknowledgments}

This work was supported by funding through NSERC. We would like to thank William Nicholson from the machine shop at University of Toronto Scarborough, who built the experimental apparatus but unfortunately passed away during this project.

\section{References}

Blanchette, F., and J. W. M. Bush (2005), Particle concentration evolution and sedimentationinduced instabilities in a stably stratified environment, Phys. Fluids, 17, 073302.

Burns, P., and E. Meiburg (2012), Sediment-laden fresh water above salt water: linear stability analysis, J. Fluid Mech., 691, 279 - 314.

Burns, P., and E. Meiburg (2015), Sediment-laden fresh water above salt water: nonlinear stability analysis, J. Fluid Mech., 762, 156 - 195.

Bradley, W. H. (1965), Vertical density currents, Science, 150(3702), 1423 - 1428.

Carey, S. (1997), Influence of convective sedimentation on the formation of widespread tephra fall layers in the deep sea, Geology, 25(9), $839-842$.

Carazzo, G., and A. M. Jellinek (2012), A new view of the dynamics, stability and longevity of volcanic clouds, Earth Planet. Sci. Lett., 325 - 326, 39 - 51.

Carazzo, G., and A. M. Jellinek (2013), Particle sedimentation and diffusive convection in volcanic ash-clouds, J. Geophys. Res., 18, $1420-1437$.

Chen, C. F. (1997), Particle flux through sediment fingers, Deep Sea Res., 44(9-10), 1645 - 1654.

Cossu, R., A. L. Forrest, H. A. Roop, G.B. Dunbar, M. J. Vandergoes, R. H. Levy, P. Stumoner and S, G. Schladow (2015), Seasonal variability in turbidity currents in Lake Ohau, New Zealand, and their influence on sedimentation, Mar. Freshwater Res., http://dx.doi.org/10.1071/MF15043.

Doroudian, B., F. Bagherimiyab, and U. Lemmin (2010), Improving the accuracy of four-receiver Acoustic Doppler Velocimeter (ADV) measurements in turbulent boundary layer flows, Limnol. Oceanogr. Methods, 8(11), 575 - 591.

Devi, T. B., and B. Kumar (2015), Turbulent flow statistics of vegetative channel with seepage, $J$. Appl. Geophys., 123, $267-276$. 
Fofonoff, N. P., and R. C. Millard Jr (1987), Algorithms for computation of fundamental properties of sea water, UNESCO technical papers in marine sciences, 44, 5 - 14.

Giovanoli, F. (1990), Horizontal transport and sedimentation by interflows and turbidity currents in Lake Geneva, in M. M. Tilzer, C. Serruya (editor), Large Lakes, Springer Verlag, 175 - 195.

Green, T. (1987), The importance of double diffusion to the settling of suspended material. Sedimentology, (34), $319-31$.

Griffiths, R. W. (1979), A note on the formation of "salt-finger" and "diffusive" interfaces in threecomponent systems, Int. J. Heat Mass Transfer, 22(12), 1687 - 1693.

Hinat, H., G. Eyal, Z. Steiner, Y. Braun, S. Shalev and B. N. Goodman-Tchernov (2015), Desert flash floods form hyperpycnal flows in the coral-rich Gulf of Aqaba, Red Sea, Earth Planet. Sci. Lett., 417, $87-98$.

Horner-Devine, A. R., R. D. Hetland and D. G. MacDonald (2015), Mixing and transport in coastal river plumes, Annu. Rev. Fluid Mech., 47, 569 - 594.

Houk, D., and T. Green (1973), Descent rates of suspension fingers, Deep Sea Res., 20, 757 - 761.

Hoyal, D. C. J. D., M. I. Bursik and J. F. Atkinson (1999a), The influence of diffusive convection on sedimentation from buoyant plumes, Mar. Geol., 159, 205 - 220.

Hoyal, D. C. J. D., M. I. Bursik and J. F. Atkinson (1999b), Settling-driven convection: A mechanism of sedimentation from stratified fluids. J. Geophys. Res., 104 (C4), 7953 - 7966.

Kuenen, PH. H. (1968), Settling convection and grain-size analysis, J. Sediment. Petrol., 38 (3), $817-831$.

Manzella, I., C. Bonadonna, J. C. Phillips and H. Monnard (2015), The role of gravitational instabilities in deposition of volcanic ash, Geology, 43.3, $211-214$.

Maxworthy, T. (1999), The dynamics of sedimenting surface gravity currents. J. Fluid Mech., 392, $27-44$.

Meiburg, E., and B. C. Kneller (2010), Turbidity currents and their deposits, Annu. Rev. Fluid Mech., 42, $135-156$. 
Mulder, T., and E. Chapron (2011), Flood deposits in continental and marine environments: character and significance, in R. M. Slatt and C. Zavala eds., Sediment transport from shelf to deep water - Revisiting the delivery system: AAPG Studies in Geology, 61, 1 - 30.

Mulder, T. and J. P. M. Syvitski (1995), Turbidity currents generated at river mouths during exceptional discharges to the world oceans, J. Geol., 103 (3), 285 - 299.

Nortek AS (2004), VECTRINO Velocimeter User Guide (Rev. C), Norway.

Nowacki, D. J., A. R. Horner-Devine, J. D. Nash and D. A. Jay (2012), Rapid sediment removal from the Columbia River plume near field, Cont. Shelf Res., 35, 16 - 28.

Parsons, J. D., and M. H. Garcia (2000), Enhanced sediment scavenging due to double-diffusive convection, J. Sediment. Res., 70 (1), 47 - 52.

Parsons, J. D., J. W. M. Bush and J. P. M. Syvitski (2001), Hyperpycnal plume formation from riverine outflows with small sediment concentrations, Sedimentology, 48 (2), 465 - 478.

Petticrew, E. L., S. J. Albers, S. A. Baldwin, E. C. Carmack, S. J. Déry, N. Gantner, K. E. Graves, B. Laval, J. Morrison, P. N. Owens, D.T. Selbie, and S. Vagle (2015), The impact of a catastrophic mine tailings impoundment spill into one of North America's largest fjord lakes: Quesnel Lake, British Columbia, Canada, Geophys. Res. Lett., 42, 3347 - 3355.

Rouhnia, M., and K. Strom (2015), Sedimentation from flocculated suspensions in the presence of settling-driven gravitational interface instabilities, J. Geophys. Res.: Oceans, 120(9), 6384 - 6404.

Ruddick, B. R., and T. G. L. Shirtcliffe (1979), Data for double diffusers: Physical properties of aqueous salt-sugar solutions, Deep Sea Res., 9(26A), 775 - 787.

Scheu, K. R., D. A. Fong, S. G. Monismith, and O. B. Fringer (2015), Sediment transport dynamics near a river inflow in a large alpine lake, Limno. Oceanogr., 60, (4), 1195 - 1211.

Schmitt, R. W. (1994), Double diffusion in oceanography, Annu. Rev. Fluid Mech., 26, 255 - 285.

Snow, K., and Sutherland, B. R. (2014), Particle-laden flow down a slope in uniform stratification. J. Fluid Mech., 755, $251-273$.

Traxler, A., S. Stellmach, P. Garaud, T. Radko and N. Brummell (2011), Dynamics of fingering convection. Part 1 Small-scale fluxes and large-scale instabilities, J. Fluid Mech., 677, 530 - 553.

Wahl, T.L., (2000), Analyzing ADV data using WinADV, paper presented at Joint Conference on Water Resources Engineering and Water Resources Planning and Management, American Society of Civil Engineers, Minneapolis, USA. 
Warrick, J. A., J. Xu, A. N. Marlene and J. L. Homa (2008), Rapid formation of hyperpycnal sediment gravity currents offshore of a semi-arid California river, Cont. Shelf Res., 28, $991-1009$.

Wells, M. G., and R. W. Griffiths (2003), Interaction of salt finger convection with intermittent turbulence, J. Geophys. Res.: Oceans, 108(C3), 1978 - 2012.

Wu, J., Liu, J. T., Shen, H., and Zhang, S. (2006). Dispersion of disposed dredged slurry in the meso-tidal Changjiang (Yangtze River) Estuary. Estuar. Coast. Shelf Sci., 70(4), 663 - 672.

Yu, X., T. J. Hsu and S. Balachandar (2013), Convective instability in sedimentation: Linear stability analysis, J. Geophys. Res.: Oceans, 118, $256-272$

Yu, X., T. J. Hsu and S. Balachandar (2014), Convective instability in sedimentation: 3-D numerical study, J. Geophys. Res.: Oceans, 119, $8141-8161$. 